\title{
KEKUATAN GESER DAN POLA PATAHAN LOOP SPACE MAINTAINER YANG DIBUAT DENGAN TEKNIK SPOT WELDING ELEKTRIK
}

\author{
Elin Karlina *, Ellyza Herda **, Heriandi Sutadi*** \\ * Bagian ITMKG Fakultas Kedokteran Gigi Universitas Padjadjaran Bandung. \\ ** Bagian IMKG Fakultas Kedokteran Gigi Universitas Indonesia Jakarta. \\ ***Bagian IKGA Fakultas Kedokteran Gigi Universitas Indonesia.
}

Elin Karlina, Ellyza Herda, Heriandi Sutadi. Kekuatan geser dan pola patahan loop space maintainer yang dibuat dengan teknik spot welding elektrik. Indonesian Journal of Dentistry 2005; 12(2):59-65.

\begin{abstract}
The aim of this research was to study the effect of spot variations on shear strength of spot weids in an electric loop space maintainer. Stainless steel wire of $0.8 \mathrm{~mm}$ dianeter and nickel chromium crown for lower second molar of temporary teeth were used. A loop $1 \mathrm{~cm}$ wide, made of $3.5 \mathrm{~cm}$ stainless steel wire, was welded with 3 dots on the crown using an electric spot welder. Each dot for each group took different spot variations from $1 \mathrm{X}-4 \mathrm{X}$. A loop space maintainer made with the usual materials and techniques as applied at the IKGA FKG UI Clinic was used as a control, with a torch as heat source. Ten specimens each were prepared for shear testing and three specimens each for metallography. Universal testing machine was used for shear strength testing at a crosshead speed of $0.5 \mathrm{~mm} / \mathrm{min}$, and SEM/EDS was used for metallography and fractography. The data were statistically analyzed with one-way ANOVA at $p=0.05$, and Tukey post hoc test. The results show that the shear strength of the welded loop space maintainer was higher than that of a soldered loop space maintainer, although the difference was not statistically significant with spot variation 1 $\mathrm{X}$. SEM/EDS analysis suggests that a new alloy forms at the contact area of welded and soldered loop space maintainer. Fractography of the joints suggests that welds are better than soldered joints, with higher ductility and toughness, as can be seen from the dimpled pattern of the welded joint and cleavage patterns in the control joints. In conclusion, the loop space maintainer is better made by welding than by soldering.
\end{abstract}

Key words : spot welding electric, loop space maintainer, joint weld

\section{Pendahuluan}

Hilangnya gigi sulung terlalu cepat sebelum waktunya (premature) karena pencabutan akan menyebabkan bergesernya gigi tetangga ke arah ruangan kosong tersebut. Untuk mencegah terjadinya pergeseran itu digunakan suatu alat yang disebut space maintainer. ${ }^{1,2}$ Terdapat berbagai jenis space maintainer dan salah satu jenis yang sering digunakan yaitu loop space maintainer karena disainnya cukup sederhana. ${ }^{1}$ Loop space maintainer seringkali dibuat dengan memadukan kawat dan mahkota logam dengan teknik penyolderan.

Penyolderan yaitu prosedur menyatukan dua atau lebih logam menggunakan bahan solder yang mempunyai titik leleh di bawah atau diatas $450^{\circ} \mathrm{C}$. 
Titik leleh bahan solder harus $50^{\circ}-100^{\circ} \mathrm{C}$ lebih rendah daripada titik leleh logam yang akan disatukan. Salah satu sumber panas yang dapat digunakan untuk memanaskan bahan solder ialah menggunakan torch. Dalam memanaskan bahan solder dibutuhkan keahlian khusus karena tidak boleh underheating maupun overheating karena dari keduanya akan didapatkan hasil penyolderan yang kurang baik. Pada pemanasan bahan solder kemungkinan akan terbentuk lapisan oksida yang akan menghambat pengaliran bahan solder cair pada celah diantaran logim yaisg, akan disatukan. Usaha untuk mencegah atiu menghilangkan terbentuknya lapisan oksida tadi ialah dengan penggunaan flux. Jarak optimal antara kedua logam yang disatukan yaitu $0,13 \mathrm{~mm}^{3-8}$

Loop space maintainer dapat dibuat dengan teknik penyolderan dan dengan teknik welding. Welding yaitu prosedur penyatuan dua atau lebih logam dengan bantuan panas, tekanan atau keduanya tanpa penggunaan bahan solder. ${ }^{4}$ Terdapat beberapa teknik welding salah satunya ialah resistance welding. Pada resistance welding dikenal adanya fluid state dan solid state tergantung dari keadaan logam pada saat disatukan. Pada fluid state dikenal adanya spot welding listrik dan laser welding. Pada spot welding listrik digunakan alat spot welder elektrik dilengkapi dua elektroda yang akan menjepit logam yang disatukan. Elektroda yang telah diberi arus listrik akan menghasilkan panas yang kemudian akan diterima logam dan digunakan untuk terjadinya interdiffusion antara logam yang disatukan. 5,9

Bagian-bagian pada unit hasil welding secara umum dapat digambarkan dalam bentuk skema pada Gambar 1.

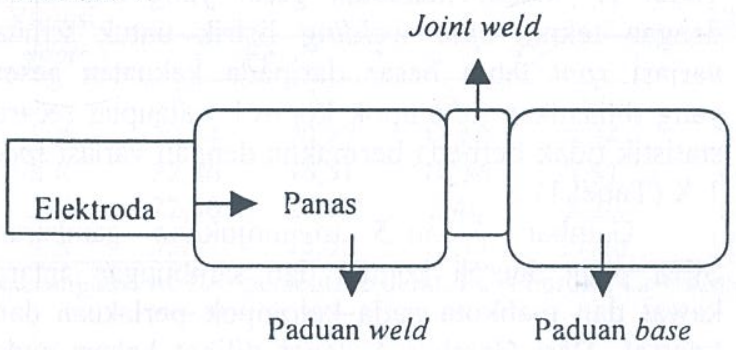

Gambar 1. Skema bagian-bagian material yang diwelding pada spot welding listrik

Sambungan antara logam-logam yang disatukan dinamakan joint weld sedangkan sambungan antara logam-logam yang disolder disebut joint solder. ${ }^{10}$

Salah satu cara untuk menentukan kualitas suatu bahan ialah dengan melihat gambaran patahannya yaitu berupa pola fraktur. Secara umum terdapat 4 jenis pola fraktur yaitu dimple, cleavage, fatigue dan dekohesif. Pada pola fraktur dimple tampak adanya gambaran cup and cone. Pola fraktur ini menunjukkan bahwa bahan tersebut kuat dan tangguh. Pada pola fraktur cleavage tampak bahwa fraktur terjadi sepanjang cleavage plane dan gambaran pola fraktur ini menunjukkan bahwa bahan bersifat brittle artinya bahan tersebut kuat tetapi tidak ulet. Selain keempat pola fraktur tadi masih terdapat pola fraktur lain yang dimasukkan kedalam jenis unik diantaranya yaitu quasi cleavage. Pada pola quasi cleavage terlihat adanya gambaran campuran antara dimple dan cleavage dan pola ini menunjukkan bahwa bahan tersebut kuat dan tangguh tetapi tidak setangguh pada pola dimple. ${ }^{11}$ Menurut penelitian yang dilakukan oleh Smith dkk (197?) didapatkan bahwa joint weld yang dihasilkan bersifat ulet begitu pula menurut penelitian yang dilakukan oleh Bertrand dkk (2001). ${ }^{12,13}$ NaBadalung dan Nicholls (1998) menemukan bahwa joint weld yang dihasilkan menunjukkan gambaran pola fraktur quasi cleavage begitu pula pada penelitian yang dilakukan oleh Chai dan Chou (1998) didapatkan bahwa pada joint weld ditemukan gambaran baik pola fraktur dimple maupun cleavage. ${ }^{14,15}$

Pada penelitian-penelitian sebelumnya telah banyak disimpulkan bahwa kekuatan ikatan yang dihasilkan dari teknik welding lebih tinggi daripada teknik penyolderan. Preston dan Reisbick (1975) membandingkan besarnya ultimate tensile strength (UTS) antara dua logam yang disambung dengan laser welding dan penyolderan. Dari penelitiannya disimpulkan bahwa nilai UTS pada logam yang disambung dengan laser welding pada umumnya lebih tinggi daripada penyolderan. ${ }^{16}$ Hasil tersebut sesuai dengan pendapat yang disampaikan oleh Smith dkk (1972), NaBadalung dan Nicholls (1998), Wang dan Chang (1998), Chai dan Chou (1998) dan Liu dkk $(2002)^{12,13,17,15,18}$. Menurut Phillips (1982) kekuatan mekanis yang dihasilkan pada teknik penyolderan sebanding dengan hasil laser welding. ${ }^{3}$

Pada penelitian ini dilakukan uji kekuatan geser terhadap spesimen untuk melihat kekuatan ikatan loop space maintainer yang dibuat dengan teknik spot welding listrik. Selain itu juga dilakukan pengamatan gambaran mikro daerah kontak pada loop space maintainer yang dibuat dengan teknik welding dan daerah sambungan pada loop space maintainer yang dibuat dengan teknik penyolderan antara kawat dan mahkota berikut uji EDS pada daerah tersebut. Uji patahan dilakukan pada spesimen yang telah dilakukan uji geser dengan 
maksud untuk mendapatkan informasi tentang sifat joint weld dan joint solder yang dihasilkan.

\section{Bahan dan Cara Kerja}

Spesimen berupa loop space maintainer yang dibuat dari kawat dan mahkota logam. Kawat yang digunakan yaitu kawat baja tahan karat tipe $18-8$ merek Dentaurum dengan diameter $0,8 \mathrm{~mm}$ sedangkan mahkota yang digunakan yaitu mahkota Nickel Chromium yang biasa digunakan sebagai restorasi gigi molar dua sulung bawah. Bentuk spesimen dapat dilihat pada Gambar 2.

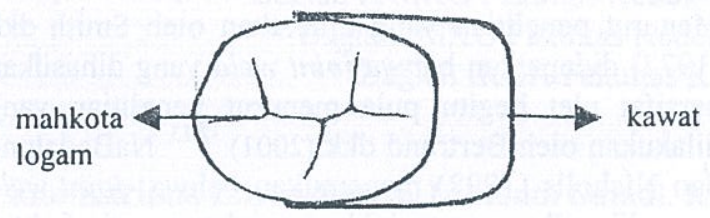

Gambar 2. Bentuk spesimen

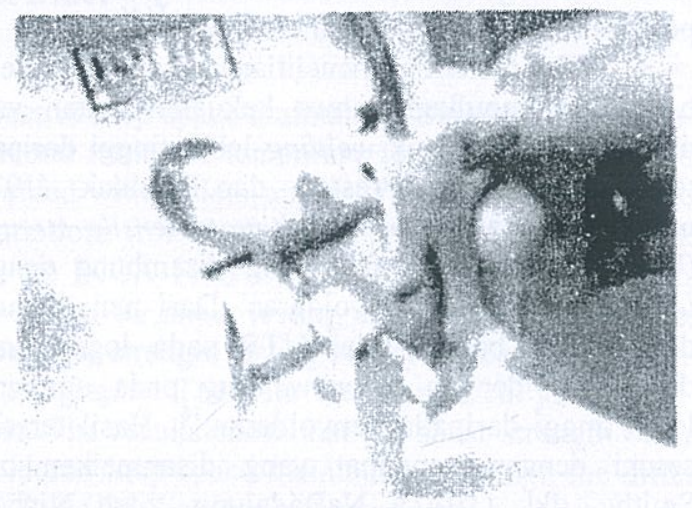

Gambar 3. Pembuatan spesimen dengan teknik spot welding listrik

Kawat dipotong sepanjang

$3,5 \mathrm{~cm}$ kemudian dibentuk loop dengan lebar $1 \mathrm{~cm}$. Untuk pengujian mekanis dilakukan uji geser pada masing-masing 10 buah spesimen untuk 4 kelompok perlakuan dan 1 kelompok kontrol. Perlakuan yang dilakukan yaitu pemberian spot welding dengan variasi spot $1 \mathrm{X}-4$ $\mathrm{X}$ untuk masing-masing titik. Spot welding listrik dilakukan menggunakan spot welder listrik merek Rocky Mountain tipe 600-1 dengan diameter spot 1 $\mathrm{mm}$ dan sambungan antara kawat dan mahkota dibuat masing-masing 3 titik untuk setiap spesimen (Gambar 3). Kontrol dibuat dengan teknik penyolderan menggunakan torch sebagai sumber panas. Bahan solder yang digunakan merek Dentaurum dipotong sepanjang $3 \mathrm{~mm}$ yang kemudian diletakkan pada daerah kontak antara kawat loop dan mahkota logam. Bahan solder kemudian dipanaskan sampai meleleh setelah sebelumnya diberi selapis tipis flux merek Oral flux. Spesimen yang telah didapat kemudian dimounting untuk uji geser. Pengujian mekanis dilakukan pada permukaan lingual untuk penyesuaian dengan alat uji geser yang menggunakan Universal Testing Machine merek Shimadzu AG 5000 E dengan kecepatan uji $0,5 \mathrm{~mm}$ permenit. Selanjutnya permukaan patahan diamati untuk mendapatkan pola/ gambaran patahannya menggunakan Scanning Electron Microscop (SEM) merek Leo 420 I dan Energy Dispesive X-Ray Spectrophotometry (EDS) merek Oxford 300 series. Data kekuatan geser dianalisis dengan uji ANOVA satu arah dan Tukey post hoc.

Spesimen untuk pengamatan gambaran mikro dibuat masing-masing 1 buah untuk keempat kelompok perlakuan dan 1 buah untuk kontrol. Cara pembuatannya sama seperti spesimen untuk uji geser. Pengamatan struktur mikro dilakukan pada daerah kontak dan sambungan antara kawat dan mahkota dengan cara memotong spesimen arah serviko oklusal tepat pada spot menggunakan diamond disc merek Edenta. Pengamatan dilakukan menggunakan SEM/EDS.

\section{Hasil}

Hasil pengujian mekanis yang dilakukan pada kelompok perlakuan dan kontrol dapat dilihat pada Tabel 1. Besar kekuatan geser yang dihasilkan dengan teknik spot welding listrik untuk semua variasi spot lebih besar daripada kekuatan geser yang dihasilkan kelompok kontrol walaupun secara statistik tidak berbeda bermakna dengan variasi spot $1 \mathrm{X}$ (Tabel 1)..

Gambar 4 dan 5 menunjukkan gambaran SEM pada daerah kontak dan sambungan antara kawat dan mahkota pada kelompok perlakuan dan kontrol. Dari Gambar 4 dapat dilihat bahwa pada daerah kontak antara kawat dan mahkota tampak terbentuknya interdiffusion zone / joint weld. Tampak pula bahwa joint weld berkontak baik dengan kawat maupun mahkota. Hasil uji EDS pada daerah tersebut menunjukkan terbentuknya suatu paduan baru (joint weld) dengan komposisi yang berbeda dengan komposisi awal bahan baik kawat maupun mahkota (Tabel 2 dan 3). Dari Tabel 2 dapat dilihat pula bahwa untuk setiap variasi spot 
Tabel I. Nilai rerata besar kekuatan geser pada loop space maintainer yang dibuat dengan teknik spot welding listrik dan kontrol

Variasi spot Besar kekuatan geser $(\mathrm{MPa}) \pm \mathrm{SD}$

$\begin{array}{ll}1 X & 48,99 \pm 4,19 \\ 2 X & 52,38 \pm 2,99 \\ 3 X & 52,80 \pm 3,64 \\ 4 X & 54,27 \pm 3,45 \\ \text { Kontrol } & 44,71 \pm 1,73\end{array}$

Tabel 3. Hasil analisis unsur bahan standar

\begin{tabular}{|c|c|c|c|c|c|c|c|c|}
\hline \multirow[b]{2}{*}{ Bahan } & \multicolumn{8}{|c|}{ Elemen (wt \%) } \\
\hline & $\mathrm{Fe}$ & $\mathrm{Cr}$ & $\mathrm{Ni}$ & $\mathrm{Si}$ & C & $\mathrm{Ag}$ & $\mathrm{Cu}$ & $\mathrm{Zn}$ \\
\hline Kawat & 72,32 & 18,15 & 8,93 & 0,46 & 0,15 & - & - & - \\
\hline Mahkota & - & 5,91 & 93,57 & 0,23 & 0,29 & - & - & - \\
\hline Solder & - & - & - & - & 0,63 & 64,97 & 6,47 & 27,93 \\
\hline
\end{tabular}

Keterangan : wt $\%=$ persentase berat, $\mathrm{Fe}=$ Ferum, $\mathrm{Cr}=\mathrm{Krom}, \mathrm{Ni}=\mathrm{Nikel}, \mathrm{Si}=$ Silikon, $\mathrm{C}=\mathrm{Karbon}$, $\mathrm{Ag}=$ Perak, $\mathrm{C}_{\mathfrak{p}} \mathrm{s}=$ Tembaga, $\mathrm{Zn}=$ Seng

Tabel 4. Hasil uji EDS pada daerah sambungan kontrol
Tabel 2. Hasil uji EDS pada joint weld loop space maintainer yang dibuat dengan teknik welding

\begin{tabular}{lcccccc}
\hline Ka- & Variasi & \multicolumn{5}{c}{ Elemen (wt \%) } \\
\cline { 3 - 7 } wat & spot & $\mathrm{Fe}$ & $\mathrm{Cr}$ & $\mathrm{Ni}$ & $\mathrm{Si}$ & $\mathrm{C}$ \\
\hline \multirow{4}{*}{ Bulat } & $1 \mathrm{X}$ & 35,39 & 14,97 & 48,78 & 0,45 & 0,42 \\
& $2 \mathrm{X}$ & 6,65 & 13,93 & 48,38 & 0,97 & 0,05 \\
& $3 \mathrm{X}$ & 5,43 & 18,20 & 15,58 & 0,50 & 0,28 \\
& $4 \mathrm{X}$ & 62,38 & 17,87 & 18,64 & 0,61 & 0,50 \\
\hline \multicolumn{6}{l}{ Keterangan $:$ wt \% }
\end{tabular}

\begin{tabular}{|c|c|c|c|c|c|c|c|c|}
\hline \multicolumn{9}{|c|}{ Elemen (wt \%) } \\
\hline $\mathrm{Fe}$ & $\mathrm{Cr}$ & $\mathrm{Ni}$ & $\mathrm{Si}$ & $\mathrm{C}$ & $\mathrm{Ag}$ & $\mathrm{Cu}$ & $\mathrm{Zn}$ & $\mathrm{O}$ \\
\hline 10,23 & 3,18 & 2,58 & 0,32 & 0,03 & 53,26 & 23,60 & 1,43 & 5,37 \\
\hline
\end{tabular}

Keterangan : wt $\%=$ persentase berat, $\mathrm{Fe}=$ Ferum, $\mathrm{Cr}=\mathrm{Krom}, \mathrm{Ni}=\mathrm{Nikel}, \mathrm{Si}=\mathrm{Silikon}, \mathrm{C}=\mathrm{Karbon}$,

Tabel 5. Hasil uji EDS patahan loop space maintainer yang dibuat dengan teknik welding

\begin{tabular}{|c|c|c|c|c|c|c|c|c|c|c|}
\hline \multirow{3}{*}{$\begin{array}{c}\text { Variasi } \\
\text { spot }\end{array}$} & \multicolumn{10}{|c|}{ Elemen (wt \%) } \\
\hline & \multicolumn{2}{|c|}{$\mathrm{Fe}$} & \multicolumn{2}{|c|}{$\mathrm{Cr}$} & \multicolumn{2}{|c|}{$\mathrm{Ni}$} & \multicolumn{2}{|c|}{$\mathrm{Si}$} & \multicolumn{2}{|c|}{$\mathrm{C}$} \\
\hline & $\mathrm{K}$ & $M$ & $\mathrm{~K}$ & $\mathrm{M}$ & $\mathrm{K}$ & $\bar{M}$ & $\mathrm{~K}$ & $\mathrm{M}$ & $\mathrm{K}$ & $\mathrm{M}$ \\
\hline $1 x$ & 32,84 & 20,27 & 11,60 & 8,24 & 55,08 & 70,88 & 0,19 & 0,29 & 0,29 & 0,32 \\
\hline $2 x$ & 22,86 & 16,51 & 10,36 & 7,51 & 66,10 & 75,33 & 0,35 & 0,26 & 0,33 & 0,39 \\
\hline $3 x$ & 22,40 & 20,94 & 8,46 & 8,20 & 68,08 & 70,19 & 0,16 & 0,28 & 0,90 & 0,39 \\
\hline $4 X$ & 33,57 & 15,55 & 13,11 & 17,88 & 52,37 & 64,46 & 0,40 & 0,87 & 0,55 & 1,24 \\
\hline
\end{tabular}

Keterangan : wt $\%=$ persentase berat, $\mathrm{Fe}=$ Ferum, $\mathrm{Cr}=\mathrm{Krom}, \mathrm{Ni}=\mathrm{Nikel}, \mathrm{Si}=$ Silikon, $\mathrm{C}=\mathrm{Karbon}$,

Tabel 6. Hasil uji EDS patahan kontrol

\begin{tabular}{|c|c|c|c|c|c|c|c|c|}
\hline \multirow[t]{2}{*}{ Bahan } & \multicolumn{8}{|c|}{ Elemen (wt \%) } \\
\hline & $\mathrm{Fe}$ & $\mathrm{Cr}$ & $\mathrm{Ni}$ & $\mathrm{Si}$ & $\mathrm{C}$ & $\mathrm{Ag}$ & $\mathrm{Cu}$ & $\mathrm{Zn}$ \\
\hline Kawat & 0,91 & 0,71 & - & 0,14 & 1,48 & 67,56 & 6,34 & 22,86 \\
\hline Mahkota & - & 0,95 & 0,95 & - & - & 65,05 & 4,94 & 28,11 \\
\hline
\end{tabular}

Keterangan : wt $\%=$ persentase berat, $\mathrm{Fe}=$ Ferum, $\mathrm{Cr}=\mathrm{Krom}, \mathrm{Ni}=\mathrm{Nikel}, \mathrm{Si}=$ Silikon, $\mathrm{C}=\mathrm{Karbon}$, $\mathrm{Ag}=$ Perak, $\mathrm{Cu}=$ Tembaga, $\mathrm{Zn}=$ Seng 


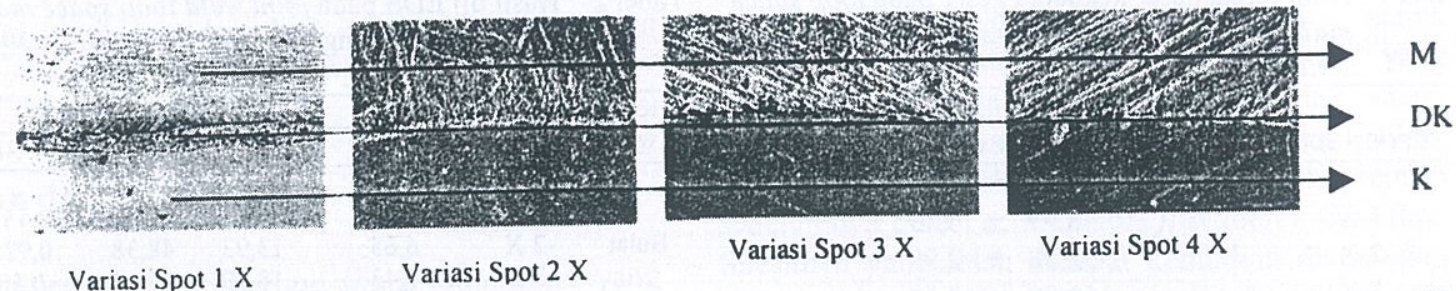

(jambar 4. Gambaran SEM daerah kontak loop space maintainer yang dibuat dengan teknik welding, perbesaran $2000 \mathrm{X}$ Keterangan : $\mathrm{M}=$ Mahkota. $\mathrm{K}=$ Kawat. $\mathrm{DK}=$ Daerah Kontak

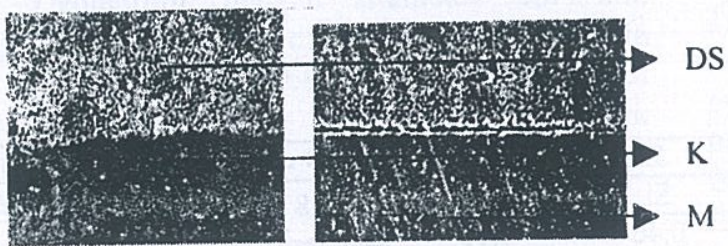

Gambar 5. Gambaran SEM daerah sambungan kontrol, perbesaran $2000 \mathrm{X}$

Ket: $M=$ Mahkota, $K=$ Kawat, DS=Daerah Sambungan

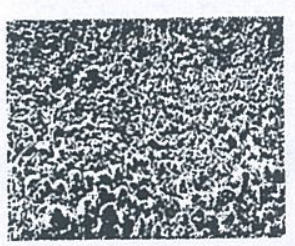

$6 a$

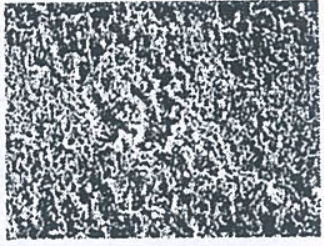

$6 \mathrm{~b}$
Gambar 6: Gambaran SEM patahan hasil welding variasi spot $1 \mathrm{X}$, perbesaran $2000 \mathrm{X}$

a) kawat, b) mahkota

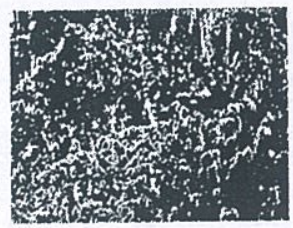

$7 \mathrm{~b}$

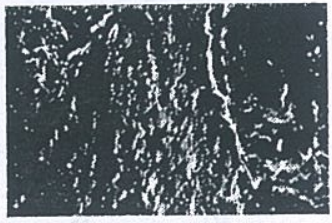

$7 \mathrm{~b}$
Gambar 7 : Gambaran SEM patahan hasil welding variasi spot $2 \mathrm{X}$, perbesaran $2000 \mathrm{X}$ a) kawat, b) mahkota

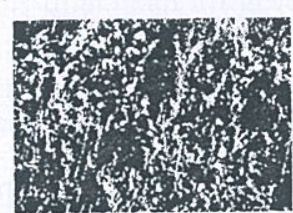

87

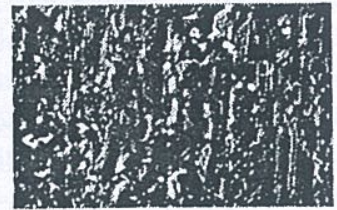

$8 b$ (jambar 8 : Gambaran SEM patahan hasil welding variasi spot $3 \mathrm{X}$, perbesaran $2000 \mathrm{X}$ a) kawat, b) mahkota

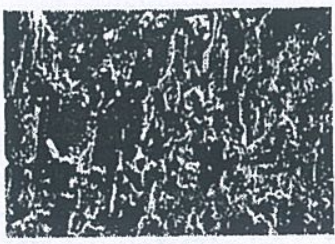

$9 \mathrm{a}$

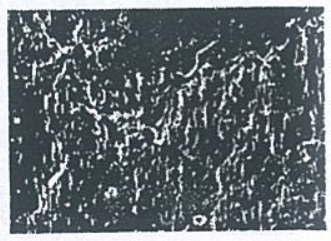

$9 \mathrm{~b}$
Gambar 9. Gambaran SEM patahan hasil welding variasi spot $4 \mathrm{X}$, perbesaran $2000 \mathrm{X}$

a) kawat, b) mahkota

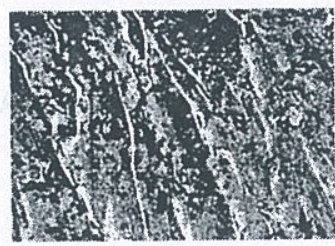

$10 \mathrm{a}$

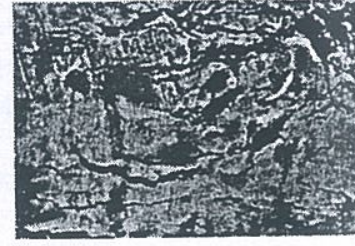

$10 \mathrm{~b}$
Gambar 10. Gambaran SEM patahan kontrol, perbesaran $2000 \mathrm{X}$

a) kawat , b) mahkota

terbentuk joint weld dengan komposisi yang berbeda-beda. Dari Gambar 5 dapat dilihat bahwa daerah sambungan yang terbentuk (joint solder) berkontak baik dengan kawat maupun mahkota. Hasil uji EDS pada daerah tersebut ternyata berbeda komposisinya baik dengan bahan solder, kawat maupun mahkota (Tabel 4 dan 3). Dari Tabel 4 tampak terlihat adanya unsur Oksigen selain unsur-unsur yang terkandung dalam bahan solder, kawat maupun mahkota logam.

Setelah dilakukan uji geser, kemudian spesimen diamati menggunakan SEM untuk dilihat gambaran patahannya dan hasilnya dapat dilihat pada Gambar 6 sampai 10. Pada Gambar 6 tampak gambaran pola dimple pada variasi spot $1 \mathrm{X}$ begitu pula pada variasi spot 2 X (Gambar 7) walaupun disertai adanya porositas terutama pada patahan mahkota. Pada variasi spot $3 \mathrm{X}$ dan $4 \mathrm{X}$ (Gambar 8 
dan 9) tampak gambaran pola quasi cleavage disertai porositas dan inklusi. Pada Gambar 10 tampak bahwa gambaran patahan kontrol memperlihatkan pola cleavage. Selain diamati menggunakan SEM, patahan kawat dan mahkota diuji EDS dan hasilnya dapat dilihat pada Tabel 5 dan 6. Dari Tabel 5 tampak bahwa fraktur pada loop space maintainer yang dibuat dengan teknik spot welding elektrik terjadi pada joint weld karena baik pada patahan kawat maupun mahkota terlihat semua unsur yang terkandung baik dalam kawat maupun mahkota. Tabel 6 memperlihatkan bahwa fraktur pada kontrol terjadi pada joint solder karena baik pada patahan kawat maupun mahkota ditemukan semua unsur yang terkandung dalam bahan solder.

\section{Pembahasan}

Dari hasil uji EDS pada joint weld (Tabel 2) terlihat bahwa interdiffusion terjadi antara kawat dan mahkota pada loop space maintainer yang dibuat dengan teknik spot welding listrik. Dengan teknik ini terbentuk suatu paduan baru dengan komposisi yang berbeda-beda untuk setiap variasi spot. Komposisi seluruh paduan baru berbeda dengan komposisi awal bahan baik kawat maupun mahkota (Tabel 3). Hal ini sesuai dengan hasil penelitian yang dilakukan oleh Smith dkk (1972) dan Bertrand dkk (2001). ${ }^{12,13}$ Dengan terbentuknya paduan baru tersebut menunjukkan bahwa ikatan yang terjadi berupa ikatan antar paduan weld dan paduan base dalam hal ini antara kawat dan mahkota.

Hasil uji EDS pada joint solder (Tabel 4) menunjukkan bahwa pada daerah tersebut terbentuk suatu paduan baru dengan komposisi yang berbeda dengan komposisi awal bahan baik kawat, mahkota maupun bahan solder. $\mathrm{Hal}$ ini sesuai dengan penelitian yang telah dilakukan oleh Chaves dkk (1998). ${ }^{19}$ Pada joint solder tampak adanya unsur Oksigen, hal ini menunjukkan bahwa pada saat bahan solder dipanaskan kemungkinan terjadi oksidasi. Dari hasil analisis unsur bahan solder (Tabel 3) terlihat bahwa kandungan dominannya berupa perak dan seng yang tergolong logam precious sedangkan kawat dan mahkota mempunyai kandungan dominan berupa Nickel dan Chromium yang tergolong logam base. Penyatuan dua logam dan golongan yang berbeda sangat berbahaya karena akan terjadi beda potensial yang akan menimbulkan arus galvanis dan terjadi korosi.

Dari gambaran pola patahan kawat maupun mahkota loop space maintainer yang dibuat dengan teknik spot welding listrik tampak adanya pola patahan dimple terutama pada variasi spot $1 \mathrm{X}$ dan 2 $\mathrm{X}$. Hal ini menunjukkan bahwa kualitas joint weld yang dihasilkan kuat dan tangguh. Pada variasi spot $3 \mathrm{X}$ dan $4 \mathrm{X}$ gambarannya memperlihatkan pola patahan quasi cleavage. Hal ini menunjukkan bahwa kualitas joint weld yang dihasilkan kuat dan tangguh tetapi tidak setangguh pada variasi spot $1 \mathrm{X}$ dan $2 \mathrm{X}$. Gambaran pola dimple yang ditunjukkan oleh variasi spot $1 \mathrm{X}$ dan $2 \mathrm{X}$ kemungkinan dapat dihubungkan dengan tingginya kandungan Nickel pada paduan baru yang terbentuk (joint weld) dibandingkan variasi spot $3 \mathrm{X}$ dan $4 \mathrm{X}$ (tabel 2) karena Nickel mempunyai peran dalam meningkatkan keuletan.

Gambaran pola patahan kontrol memperlihatkan gambaran cleavage, hal ini menunjukkan bahwa kualitas joint solder yang dihasilkan bersifat brittle artinya bahan tersebut kuat tetapi tidak tangguh. Untuk lebih mengetahui lebih jelas lagi tentang karakteristik joint weld maupun joint solder tersebut perlu dilakukan penelitian lebih lanjut.

Hasil uji EDS baik pada patahan kawat maupun mahkota untuk loop space maintainer yang dibuat dengan teknik spot welding listrik tampak bahwa fraktur terjadi pada joint weld (Tabel 5). Hal ini menunjukkan bahwa ikatan antara joint weld baik terhadap kawat maupun mahkota cukup kuat. Dari Tabel 6 terlihat pula bahwa fraktur pada kontrol terjadi pada joint solder, hal ini menunjukkan bahwa ikatan antara joint solder terhadap kawat maupun mahkota cukup kuat. Besar kekuatan geser yang dihasilkan kontrol ternyata lebih kecil daripada teknik spot welding listrik kemungkinan disebabkan karena ikatan antara joint solder dengan kawat maupun mahkota lebih rendah dibandingkan ikatan antara joint weld dengan kawat maupun mahkota.

\section{Kesimpulan}

Dari penelitian ini dapat diambil beberapa kesimpulan sebagai berikut.

1. Kekuatan geser yang dihasilkan loop space maintainer yang dibuat dengan teknik spot welding listrik lebih besar daripada kontrol.

2. Ditinjau dari kualitas bahan sambungan yang dihasilkan ternyata joint weld lebih kuat dan tangguh daripada joint solder terutama pada variasi spot $1 \mathrm{X}$ karena porositas yang terjadi sangat minimal.

3. Dianjurkan untuk menggunakan teknik spot welding listrik variasi spot $1 \mathrm{X}$ dalam pembuatan loop space maintainer karena selain kualitas 
bahan sambungan yang dihasilkan jauh lebih tangguh juga pekerjaan lebih mudah dan cepat.

\section{Daftar Pustaka}

1. Mathewson RJ, Primosch RE. Fundamentals of Pediatric Dentistry. $3^{\text {rd }}$ ed. St. Louis: Quintessence Publishing Co, Inc. 1995: 326-38

2. Finn SB. Clinical Pedodontics. $4^{\text {th }}$ ed. Philadelphia: WB. Saunders Company. 1973: 342-53

3. Phillips RW. Science of Dental Materials. $8^{\text {th }}$ ed. Philadelphia: WB. Saunders Company 1982: 534-46

4. Anusavice KJ. Phillip's Science of Dental Materials . $10^{\text {th }}$ ed. Philadelphia: WB. Saunders Company . 1996: 619-29

5. Darvel BW. Materials Science for Dentistry . $6^{\text {th }}$ ed. Hong Kong: The University of Hong Kong Press . 2000: 414-9

6. O'Brien WJ . Dental Materials and Their Selection $3^{\text {rd }}$ ed. Chicago: Quintessence Publishing $\mathrm{Co}$, Inc. 2002: 249-57

7. Craig RG. Restorative Dental Materials. $10^{\text {th }}$ ed. St. Louis: Mosby 1997: 408-9, $42-8$

8. Craig RG. Restorative Dental Materials. $11^{\text {th }}$ ed. St. Louis: Mosby . 2002 : 495-9, 543-6.

9. Metals Handbook . $9^{\text {th }}$ ed. Welding, Brazing and Soldering. USA: ASM International. 1983; (6): 1525-34.
10. Welding Handbook . $7^{\text {th }}$ ed. Fundamentals of Welding. Miami Florida : American Welding Society. 1982; (1): 101-40.

11. ASM Handbook. Formerly Ninth Edition . Metals Handbook.. Fractography. USA: ASM International 1992: (12):12-21.

12. Smith DL, Burnett AP dan Gordon TE. Laser Welding of Gold Alloys J Dent Res 1972; 51: 161-7.

13. Bertrand C, Petitcorps L, Albingre L.The laser welding technique applied to the non precious dental alloys: procedure and results. J Brit Dent 2001; 190: 151-5.

14. NaBadalung DP, Nicholls JI. Laser Welding of a cobalt - chromium removable partial denture alloy. J Prosth Dent 1998; 79 : 285-90.

15. Chai $T$ dan Chou $C K$. Mechanical properties of laser - welded cast titanium joints under different conditions. J Prosth Dent 1998 ; 79 : 477-83.

16. Preston JD dan Reisbick MH. Laser Fusion of Selected Dental Casting Alloys. J Prosth Dent 1975 ; 54 : 232-8.

17. Wang RR dan Chang CT. Thermal modeling of laser welding for titanium dental restorations.' $J$ Prosth Dent 1998; 79: 335-42.

18. Liu J, Watanabe I, Yoshida K. Joint strength of laser welded titanium. J Dent Mat 2002 ; 18 : 143-8.

19. Chaves M, Vermilyea SG, Papazoglou E. Effects of three soldering technique on the strength of high-palladium alloy solder joints. $J$ Prosth Dent 1998; 79: 677-84. 